\title{
Detection of millimetric deformation using a terrestrial laser scanner: experiment and application to a rockfall event
}

\author{
A. Abellán ${ }^{1}$, M. Jaboyedoff ${ }^{2}$, T. Oppikofer ${ }^{2}$, and J. M. Vilaplana ${ }^{1}$ \\ ${ }^{1}$ RISKNAT group \& GEOMODELS Institute, Department of Geodynamics and Geophysics, University of Barcelona, Spain \\ ${ }^{2}$ Institute of Geomatics and Risk Analysis (IGAR), University of Lausanne, Switzerland
}

Received: 21 October 2008 - Revised: 25 February 2009 - Accepted: 27 February 2009 - Published: 17 March 2009

\begin{abstract}
Terrestrial laser scanning (TLS) is one of the most promising surveying techniques for rockslope characterization and monitoring. Landslide and rockfall movements can be detected by means of comparison of sequential scans. One of the most pressing challenges of natural hazards is combined temporal and spatial prediction of rockfall. An outdoor experiment was performed to ascertain whether the TLS instrumental error is small enough to enable detection of precursory displacements of millimetric magnitude. This consists of a known displacement of three objects relative to a stable surface. Results show that millimetric changes cannot be detected by the analysis of the unprocessed datasets. Displacement measurement are improved considerably by applying Nearest Neighbour (NN) averaging, which reduces the error $(1 \sigma)$ up to a factor of 6 . This technique was applied to displacements prior to the April 2007 rockfall event at Castellfollit de la Roca, Spain. The maximum precursory displacement measured was $45 \mathrm{~mm}$, approximately 2.5 times the standard deviation of the model comparison, hampering the distinction between actual displacement and instrumental error using conventional methodologies. Encouragingly, the precursory displacement was clearly detected by applying the NN averaging method. These results show that millimetric displacements prior to failure can be detected using TLS.
\end{abstract}

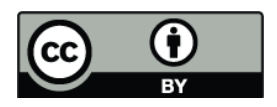

Correspondence to: A. Abellán (antonio.abellan@ub.edu)

\section{Introduction}

Terrestrial laser scanning (TLS) is one of the most promising surveying techniques for rockslope characterization and monitoring (Bitelli et al., 2004; Biasion et al., 2005; Abellán et al., 2006). TLS acquires a high-resolution point cloud of the survey scene based on the measurement of the time-offlight of an infrared pulse emitted in a known direction (Slob and Hack, 2004). Three dimensional variations of the terrain (involving landslide and rockfall movements) can be detected by means of comparison of sequential terrestrial laser scans (Bauer et al., 2005; Rosser et al., 2005; Oppikofer et al., 2008a).

One of the present challenges in rockfall hazard is combined temporal and spatial prediction of rockfalls. An important advance in the former is the apparent consistency in the tertiary creep stage (Terzaghi, 1950) of brittle failure: an acceleration of the displacement rates prior to a failure. Current works on failure forecasting are mainly based on establishing inverse velocity against time relationships (Saito, 1969; Fukuzono, 1985). The pre-failure deformation of monitored rockfalls ranges from a few centimetres to several decimetres, proportional to event size (Zvelebil and Moser, 2001; Crosta and Agliardi, 2003; Rose and Hungr, 2007). One of the limitations of these works is that the rates of displacement were acquired on single points only (i.e. extensometers, GPS nodes and/or total stations). The measurement of precursory displacements over great extensions seems only to be possible with new remote sensing techniques, i.e. Ground-Based Interferometric Synthetic Aperture Radar (GB-InSAR) and/or terrestrial laser scanning (TLS).

Despite these advances in rockfall forecasting, spatial prediction of future rockfalls over wide areas is still unfeasible.

Published by Copernicus Publications on behalf of the European Geosciences Union. 

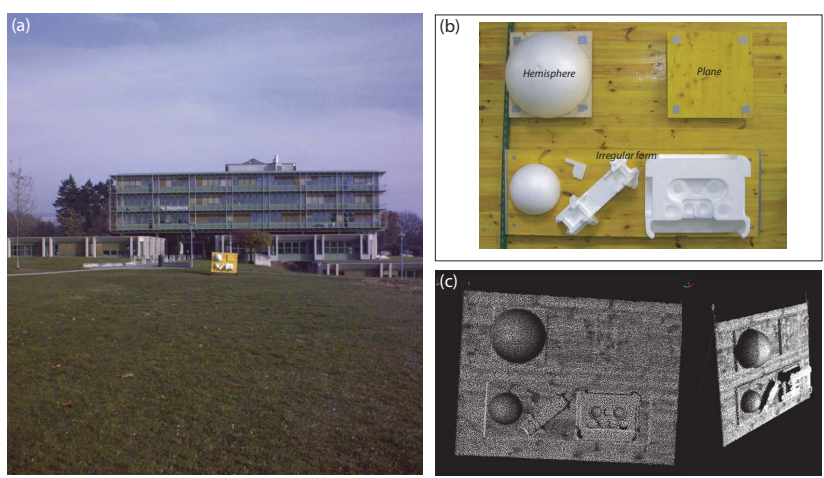

Fig. 1. (a) General overview of the experimental setup (range $=50 \mathrm{~m}$ ) (b) Zoom of the scanned area showing the 3 moving objects on the fixed part. (c) Perspective views of the TLS point cloud.

Current efforts in source area determination are still based on well known techniques like the study of historical records (Ibsen and Brunsden, 1996), statistics (i.e. multivariate analysis, Carrara, 1983) or heuristic techniques (i.e. expert criteria, Soeters and Van Westen, 1996). A pioneering study that detects precursory patterns in wide areas using TLS was made by Rosser et al. (2007), who observed a precursory pattern of small rockfalls leading to larger failures.

One question that remains to be resolved is as follows: is the instrumental error of TLS systems small enough to detect pre-failure deformation on rockslope surfaces? Under normal conditions, the TLS model comparison error is of the order of centimetres (Fiani and Siani, 2005; Teza et al, 2007). Under these circumstances, the instrumental error may mask precursory deformation. This is due to the fact that conventional comparisons do not fully exploit one of the main advantages of TLS: the high quantity and density of measurements (Monserrat and Crosetto, 2008). As a consequence, errors in comparison can potentially be reduced by using the information of the neighbouring points, i.e. by filtering or interpolation (Lindenbergh and Pfeifer, 2005).

The aims of this study are: (i) to develop a methodology that is able to detect millimetric/centimetric scale deformation on rockslopes using TLS and (ii) to apply this methodology to detect a precursory deformation on a real falling slope. An outdoor experiment with controlled conditions of range and deformation was performed in order to simulate small scale deformation prior to failure. Two different data analysis techniques were employed: the analysis of the original, unprocessed datasets (referred to here after as RAW data) and a filtering technique based on the average value of the Nearest Neighbours. Finally, these techniques were applied to the detection of the precursory deformation of a $50 \mathrm{~m}^{3}$ rockfall on a basalt rockface at Castellfollit de la Roca, Catalonia, Spain.

\section{Material and methods}

\subsection{Instrument characteristics}

The terrestrial laser scanning system used is an Optech ILRIS3D, which consists of a transmitter/receiver of infrared laser pulses (1535 nm wavelength) and scanning optics. Distance measurement $(\rho)$ is based on the time-of-flight $(\Delta t)$ of the laser pulse to travel and reflect from the surface of interest (Eq. 1):

$\rho=c \cdot \Delta t / 2$,

where $c=$ speed of light.

Location of each point is acquired in a polar coordinate system $(\rho, \vartheta, \varphi)$. The horizontal and vertical angles $(\vartheta$ and $\varphi$, respectively) are modified by the scanner device using an internal system of rotating mirrors. In our study, these angles are transformed into a Cartesian coordinate system $(x, y, z)$ (Eq. 2):

$[x y z]^{t}=\rho[\cos \theta \cos \varphi, \cos \theta \operatorname{sen} \varphi, \operatorname{sen} \varphi]^{t}$

The reflectivity, i.e. the amount of reflected signal with respect to the emitted one, is also recorded for each point. It mainly depends on the range, angle of incidence, material moisture and object material. Compared to conventional surveying methods, a TLS shows a very high data acquisition speed (up to 2500 points/second). Technical characteristics of the ILRIS3D supplied by the manufacturer show high maximum range (up to $700 \mathrm{~m}$ for natural slopes) and point accuracy of $7 \mathrm{~mm}$ at $50 \mathrm{~m}$. The object surface orientation influences the accuracy: as the beam footprint becomes increasingly elongate, the error is increased (Ingensand et al., 2006). A brief discussion on TLS principles and performances is beyond this paper, but can be found in Teza et al. (2007).

\subsection{Experimental setup}

The experiment was performed at the Lausanne University campus. It consists of a simulation of a pre-failure deformation on a rockslope by a simulated displacement of three objects, (i) a plane, (ii) a hemisphere and (iii) an irregular form, relative to a fixed, stable and vertical plane (Fig. 1). The displacements of the three objects range between 5 and $25 \mathrm{~mm}$, with an increment of $5 \mathrm{~mm}$ between each scan.

After each induced displacement, a TLS point cloud was acquired (referred to here after as data point cloud) and compared with the initial point cloud captured at $0 \mathrm{~mm}$ displacement (referred to here after as reference point cloud). The objects were scanned at 35500 points $/ \mathrm{m}^{2}$, or in terms of a square grid at 1 point every $5.3 \mathrm{~mm}$ at a distance of $50 \mathrm{~m}$ between the TLS and the fixed plane.

The real displacement was assessed with callipers. The repeatability of the calliper measurements is $\sim 0.1 \mathrm{~mm}$ and 
given that this value is approximately 2 orders of magnitude more accurate than the TLS instrumental error, the calliper value can be considered hereafter as the real displacement value.

\subsection{Displacement computation}

The TLS displacement values were calculated for each object using two different approaches: (a) RAW data, and (b) average of the 24 Nearest Neighbours.

The RAW data displacements between the reference and data point clouds were computed in Innovmetrics PolyWorks ${ }^{\circledR}$ v.9 software using a conventional methodology (data vs. reference comparison). Difference is therefore calculated as normal to the stable base plane and direction of displacement. For each object, the average displacement $(\mu)$ and standard deviation of displacement measures $(\sigma)$ are calculated.

In order to reduce the error in RAW data comparison, a Nearest Neighbour (NN) averaging technique was applied. This technique consists of a (i) data interpolation to a square grid, (ii) a search for the $k$ surrounding points (Davis, 1975), and (iii) the calculation of the average value of the NN for each point, excluding the edges. In order to obtain a good agreement between accuracy and resolution, different $k$ values were tested in the experimental case study. Algorithms that involved low numbers of $\mathrm{NN}(k=8,3 \times 3 \mathrm{NN})$ retained significant noise. By contrast, algorithms that involved a larger number of $\mathrm{NN}(k=35,6 \times 6 \mathrm{NN})$ masked local scale displacements. A $k$ value of $24(5 \times 5 \mathrm{NN})$ was selected as an optimal compromise.

Error in comparison of the sequential scans is a function of the instrumental error, alignment error and modelling error (Teza et al., 2007). Given that the TLS and the object remained at the same position during the whole experiment, alignment error is negligible. Moreover, modelling error was minimized using a consistent geometry and a very large number of points. The TLS instrumental error was calculated as the standard deviation of the distance between the points of the fixed plane and the best fit plane to these points $(1 \sigma=7.2 \mathrm{~mm}$, Table 1$)$.

\section{Results}

\subsection{Displacements based on RAW data}

The average displacements obtained from RAW data comparisons between the reference and data point clouds are shown in Table 1. Figure 2a displays the scatter of binned RAW data displacement values of the plane, for each displacement step ( 5 to $25 \mathrm{~mm}$ by $5 \mathrm{~mm}$ increments). A fitted Gaussian distribution is also provided. Figure $2 \mathrm{~b}$ displays $R A W$ data vs. real value measurements. The three objects (plane, sphere and irregular form) show significant lin- (a)

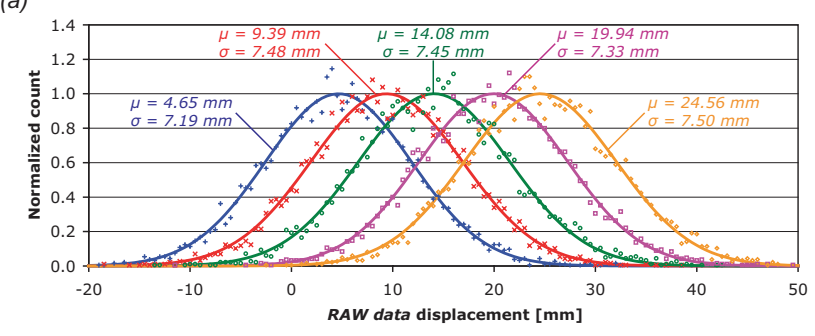

(b)

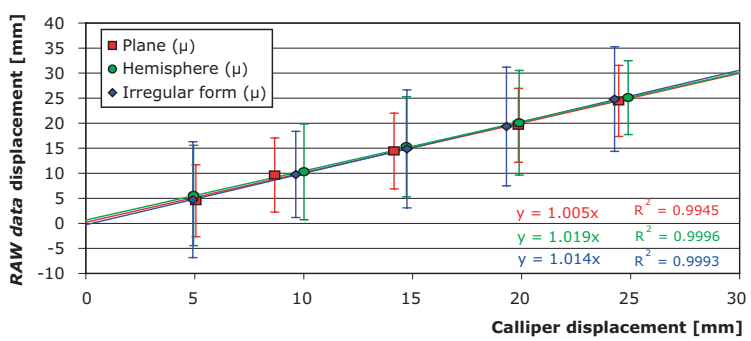

Fig. 2. (a) Normalised number of observations ( $\mathrm{Y}$ axis) for each interval ( $0.5 \mathrm{~mm}$ classes) of the RAW data (plane object). Curves show fitted Gaussian distributions ( $\mu=$ mean value; $\sigma=$ standard deviation) for $5,10,15,20$ and $25 \mathrm{~mm}$ (from left to right, respectively). (b) Mean value of the $R A W$ data displacements vs. real value of the displacement (calliper) for the three objects (plane, hemisphere and a irregular form). The error bars represent $1 \sigma$ standard deviation (7.4, 10.1 and $11.2 \mathrm{~mm}$ respectively). Standard deviation for the plane is significantly lower than for the hemisphere and the irregular form.

ear correlation between the actual and the average TLS value $\left(R^{2}>0.99\right)$.

Both figures show that the range of the values of the RAW data $(7.4 \mathrm{~mm}<\sigma<11.2 \mathrm{~mm}$ ) is of the same order of magnitude as the first and second deformation increments of the experiment ( 5 and $10 \mathrm{~mm}$, respectively). As a result, the real displacement is masked by this high variability.

Figure 3 shows a comparison between reference and data point clouds for displacements ranging from 5 to $25 \mathrm{~mm}$. As stated before, the real displacements in Fig. 3a and b (5 and $10 \mathrm{~mm}$, respectively) are masked by the scattering of the RAW data. In these figures it is difficult to differentiate moving and fixed parts. However, the induced displacements can be detected in Fig. 3c $(15 \mathrm{~mm})$, and are clearly visible in Fig. 3d and e (20 and $25 \mathrm{~mm}$, respectively).

Summarizing, the value above which precursory displacements can be detected (referred to here after as threshold value) was set at $15 \mathrm{~mm}$. This value corresponds to twice the standard deviation of the model comparison (Eq. 3).

Threshold value $=2 \cdot \sigma_{\text {model }}$ comparison 
Table 1. (a) TLS measurements (mm). (b) Calliper measurements (mm).

\begin{tabular}{|c|c|c|c|c|c|c|c|c|c|c|c|c|}
\hline \multicolumn{8}{|c|}{ (a) TLS measurements (mm) } & \multicolumn{5}{|c|}{ (b) Calliper measurements (mm) } \\
\hline & variable & $\begin{array}{r}\text { Num. of } \\
\text { points }\end{array}$ & $\begin{array}{r}\text { Mean value } \\
(\mu)\end{array}$ & $\begin{array}{r}\text { St. Dev. } \\
(\sigma)\end{array}$ & $\begin{array}{l}\text { Min. } \\
\text { value }\end{array}$ & $\begin{array}{l}\text { Max. } \\
\text { value }\end{array}$ & $\begin{array}{r}\text { Mean } \\
\text { displace- } \\
\text { ment }\end{array}$ & a & $\mathrm{b}$ & $\mathrm{c}$ & $\mathrm{d}$ & $\begin{array}{r}\text { Mean } \\
\text { displace- } \\
\text { ment }\end{array}$ \\
\hline \multirow{4}{*}{$0 \mathrm{~mm}$} & Fixed part & 43561 & -0.31 & 7.21 & -36.19 & 32.20 & 0.00 & - & - & - & - & - \\
\hline & Plane & 6971 & -0.11 & 7.26 & -41.46 & 32.45 & 0.20 & 17.07 & 17.10 & 19.12 & 17.70 & 0.00 \\
\hline & Hemisphere & 6175 & -0.62 & 9.67 & -78.76 & 71.01 & -0.31 & 18.63 & 18.23 & 18.80 & 18.97 & 0.00 \\
\hline & Irregular & 20049 & -0.37 & 11.46 & -234.16 & 195.79 & -0.06 & 19.20 & 18.85 & 19.57 & 18.68 & 0.00 \\
\hline \multirow{4}{*}{$5 \mathrm{~mm}$} & Fixed part & 75741 & -0.06 & 7.28 & -27.69 & 27.51 & 0.00 & - & - & - & - & - \\
\hline & Plane & 6670 & 4.48 & 7.19 & -21.90 & 32.01 & 4.53 & 21.95 & 22.07 & 24.10 & 23.05 & 5.05 \\
\hline & Hemisphere & 6245 & 5.52 & 10.02 & -74.84 & 87.34 & 5.57 & 23.40 & 23.25 & 23.68 & 24.05 & 4.94 \\
\hline & Irregular & 19364 & 4.67 & 11.56 & -207.78 & 229.83 & 4.73 & 24.08 & 23.65 & 24.95 & 23.24 & 4.91 \\
\hline \multirow{4}{*}{$10 \mathrm{~mm}$} & Fixed part & 48129 & -0.47 & 7.21 & -40.45 & 46.57 & 0.00 & - & - & - & - & - \\
\hline & Plane & 6943 & 9.18 & 7.40 & -21.82 & 38.30 & 9.65 & 26.90 & 22.27 & 29.03 & 27.47 & 8.67 \\
\hline & Hemisphere & 6101 & 9.83 & 9.57 & -49.09 & 50.67 & 10.30 & 28.45 & 28.45 & 28.70 & 29.08 & 10.01 \\
\hline & Irregular & 20031 & 9.20 & 11.09 & -209.81 & 229.71 & 9.67 & 28.85 & 28.83 & 29.55 & 27.60 & 9.63 \\
\hline \multirow{4}{*}{$15 \mathrm{~mm}$} & Fixed part & 47513 & -0.41 & 7.15 & -40.05 & 33.84 & 0.00 & - & - & - & - & - \\
\hline & Plane & 6823 & 14.04 & 7.54 & -13.76 & 42.15 & 14.45 & 30.60 & 31.98 & 33.74 & 31.25 & 14.14 \\
\hline & Hemisphere & 6114 & 14.90 & 10.01 & -72.53 & 57.90 & 15.31 & 33.30 & 33.18 & 33.38 & 33.60 & 14.71 \\
\hline & Irregular & 19444 & 14.47 & 11.79 & -206.78 & 246.84 & 14.88 & 33.60 & 33.68 & 34.38 & 33.57 & 14.73 \\
\hline \multirow{4}{*}{$20 \mathrm{~mm}$} & Fixed part & 44608 & 0.22 & 7.10 & -38.72 & 36.74 & 0.00 & - & - & - & - & - \\
\hline & Plane & 6990 & 19.79 & 7.38 & -11.67 & 50.24 & 19.58 & 37.68 & 37.13 & 39.23 & 36.38 & 19.85 \\
\hline & Hemisphere & 6036 & 20.30 & 10.44 & -63.85 & 103.17 & 20.09 & 38.65 & 37.75 & 38.68 & 39.05 & 19.88 \\
\hline & Irregular & 19084 & 19.57 & 11.85 & -209.06 & 237.96 & 19.35 & 38.78 & 37.10 & 39.58 & 38.04 & 19.30 \\
\hline \multirow{4}{*}{$25 \mathrm{~mm}$} & Fixed part & 43825 & -0.04 & 7.13 & -41.24 & 29.79 & 0.00 & - & - & - & - & - \\
\hline & Plane & 6903 & 24.46 & 7.48 & -2.56 & 54.67 & 24.51 & 41.40 & 41.93 & 43.90 & 41.58 & 24.45 \\
\hline & Hemisphere & 6108 & 25.11 & 10.69 & -58.36 & 102.49 & 25.16 & 43.75 & 42.90 & 43.43 & 44.08 & 24.88 \\
\hline & Irregular & 19395 & 24.82 & 12.09 & -200.08 & 243.48 & 24.86 & 43.48 & 42.10 & 44.78 & 42.97 & 24.26 \\
\hline
\end{tabular}

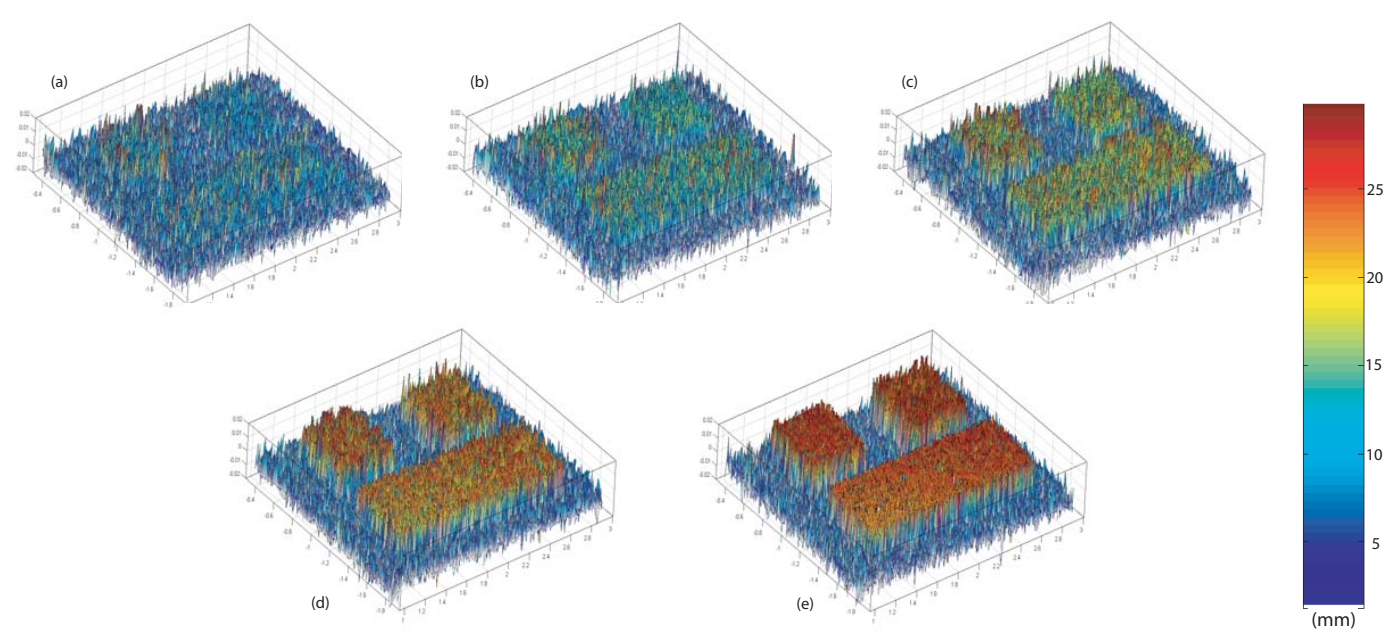

Fig. 3. RAW data displacement measurements $(7.4 \mathrm{~mm}<\sigma<11.2 \mathrm{~mm})$ for different induced displacements: (a) $5 \mathrm{~mm}$, (b) $10 \mathrm{~mm}$, (c) $15 \mathrm{~mm}$, (d) $20 \mathrm{~mm}$, (e) $25 \mathrm{~mm}$. The colour scale (in millimeters) indicates displacements of up to $30 \mathrm{~mm}$. 


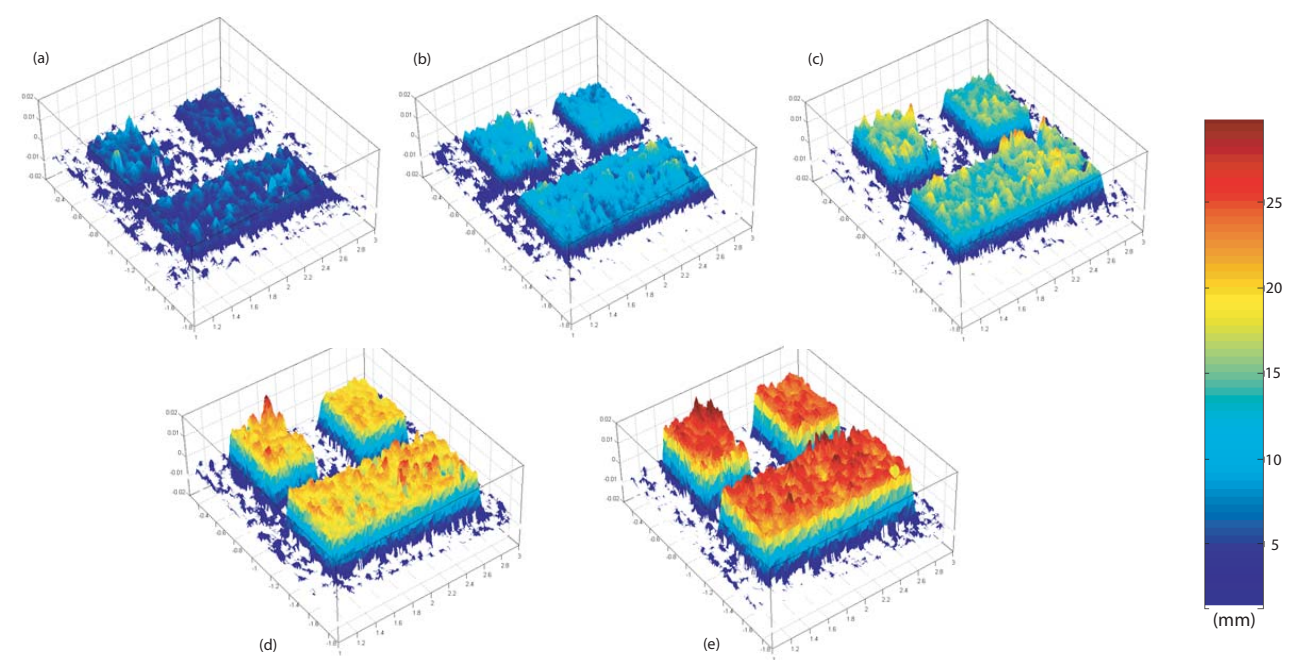

Fig. 4. Displacement measurements after the $5 \times 5$ closest neighbours averaging for different induced displacements $\left(\sigma_{\text {plane }}=1.3 \mathrm{~mm}\right)$ : $(\mathbf{a})$ $5 \mathrm{~mm}$, (b) $10 \mathrm{~mm}$, (c) $15 \mathrm{~mm}$, (d) $20 \mathrm{~mm}$, (e) $25 \mathrm{~mm}$. The colour scale (in millimeters) indicates displacements of up to $30 \mathrm{~mm}$.

\subsection{Nearest Neighbour averaging}

Figure 4 shows the comparisons between reference and data point clouds for displacements ranging from 5 to $25 \mathrm{~mm}$ using the $5 \times 5$ nearest neighbour averaging algorithm. As the instrumental error is filtered out using this method, the real displacement is visible in Fig. 4a to e (5, 10, 15, 20 and $25 \mathrm{~mm}$, respectively).

In contrast to the low precision (or high variability) obtained using conventional methodologies (Fig. 3), the displacement was more accurately computed after $\mathrm{NN}$ averaging, even for the smallest displacement value ( $5 \mathrm{~mm}$, Fig. 4a). The standard deviation of the model comparison is $1.3 \mathrm{~mm}$, six times more accurate using $\mathrm{NN}$ averaging rather than conventional methodologies. Using Eq. 3, the threshold value using $\mathrm{NN}$ technique was potentially set at $2.6 \mathrm{~mm}$.

\section{Application to a rockfall event}

The basalt cliff at Castellfollit de la Roca, Catalonia, Spain (Fig. 5a) has been monitored using TLS by the RISKNAT group since March 2006. The research is focused on quantifying the volume and frequency of current failures in order to estimate future rockfall hazard concern surrounds houses located at the edge of the rockface that could be affected by cliff retreat. The historical rockfall record at this site shows: (i) few rockfall events $\left(\sim 1 \mathrm{~m}^{3}\right)$ per year; (ii) medium scale rockfalls $\left(\sim 50\right.$ to $\left.250 \mathrm{~m}^{3}\right)$ with a period of recurrence of about 10 years; (iii) larger scale rockfalls $(\sim 1000$ to $2500 \mathrm{~m}^{3}$ ) with a recurrence of 50 years (Abellán et al., 2008). A set of $50 \mathrm{~m}^{3}$ columnar basalt blocks fell (Fig. 5b), after a period of continuous rainfall (100 $\mathrm{mm}$ in 1 week) in April 2007, which we analyze below.

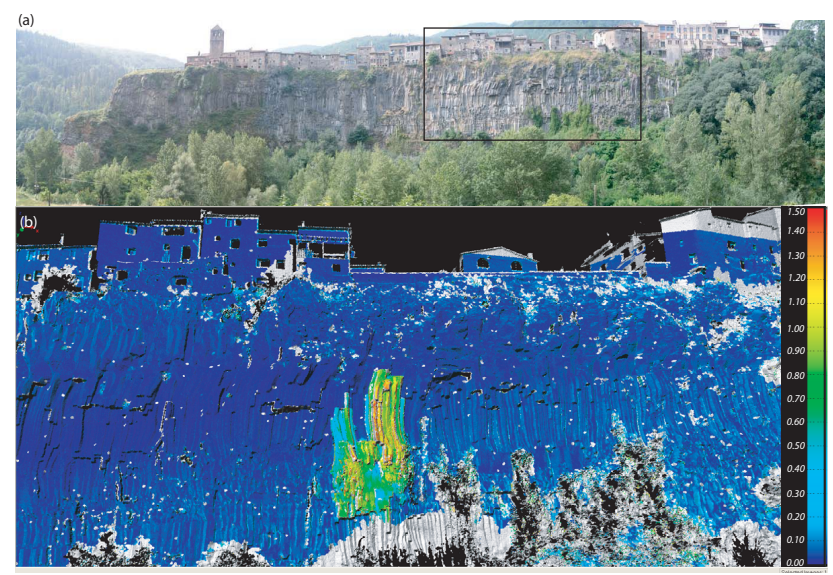

Fig. 5. (a) Study area: Basaltic cliff at Castellfollit de la Roca. The frame corresponds to (b) Comparison of TLS models (iii) and (iv) (March and April 2007, respectively) showing the $50 \mathrm{~m}^{3}$ rockfall event in April 2007. Colour scale from 0 (blue) to $1.5 \mathrm{~m}$ (red).

TLS point clouds were acquired using an Optech ILRIS3D TLS (i) in September 2006, (ii) in December 2006, (iii) a few days before and (iv) a few days after the April 2007 failure. The scans were performed from the opposite side of the valley at a mean range to the rockface of $190 \mathrm{~m}$. The effective resolution (mean point spacing) on the cliff was defined as $70 \mathrm{~mm}$. The (iii) point cloud served as a reference for comparison with datasets (i) and (ii).

The comparison of the reference and data point clouds using the RAW data is shown in Fig. 6. Figure. 6a and $b$ suggest that the cliff underwent deformation in the 6 months prior to the failure. However, owing to the high variability discussed in Sect. 2 and 3, we were unable to clearly delimit the extent 


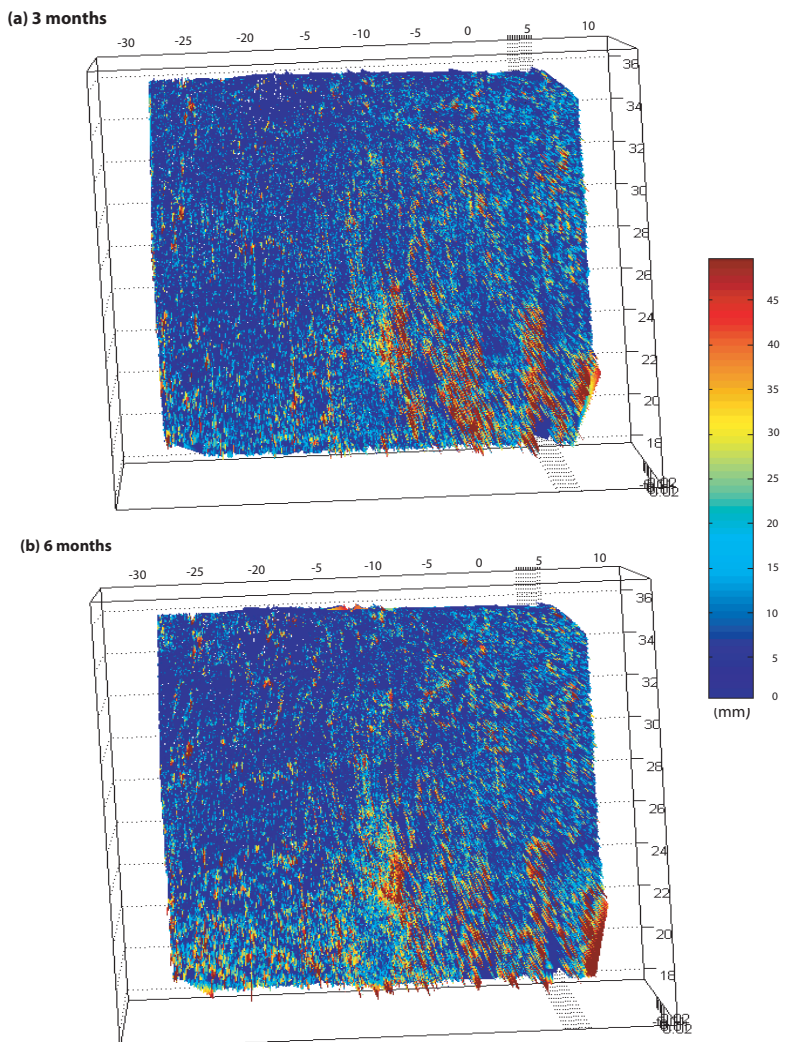

Fig. 6. RAW data displacement measurements prior to the $50 \mathrm{~m}^{3}$ rockfall; (a) cumulated displacement for 3 months comparison; (b) cumulated displacement for 6 months comparison. Precursory displacement cannot be clearly detected using this approach. $\sigma_{\text {RAW data }}=18.0 \mathrm{~mm}$.

of deformation. The model comparison error as described by $\sigma$ is calculated for the stable parts of the cliff, as $18.0 \mathrm{~mm}$. Equation 3 shows that precursory displacement under $2 \cdot \sigma$ cannot be detected using this approach. This threshold is therefore set at in $36.0 \mathrm{~mm}$.

A detailed analysis of the reference and data point clouds, using the 24 Nearest Neighbour averaging, shows a deformation of the cliff sector (Fig. 7). The calculated maximum precursory displacement was $45 \mathrm{~mm}$ (Fig. 7b), a value slightly higher than that of the threshold mentioned above. For this reason, the attempts to isolate the precursory displacement from the instrumental error using conventional methodologies were unsuccessful. Error using the NN averaging technique $(1 \sigma)$ over a stable part was calculated as $6.4 \mathrm{~mm}$, which is 3 times more accurate than with conventional methodologies.

\section{Discussion and conclusions}

Standard deviation of the instrumental error was calculated as $7.2 \mathrm{~mm}$ at a distance of $50 \mathrm{~m}$ (Table 1). This value is

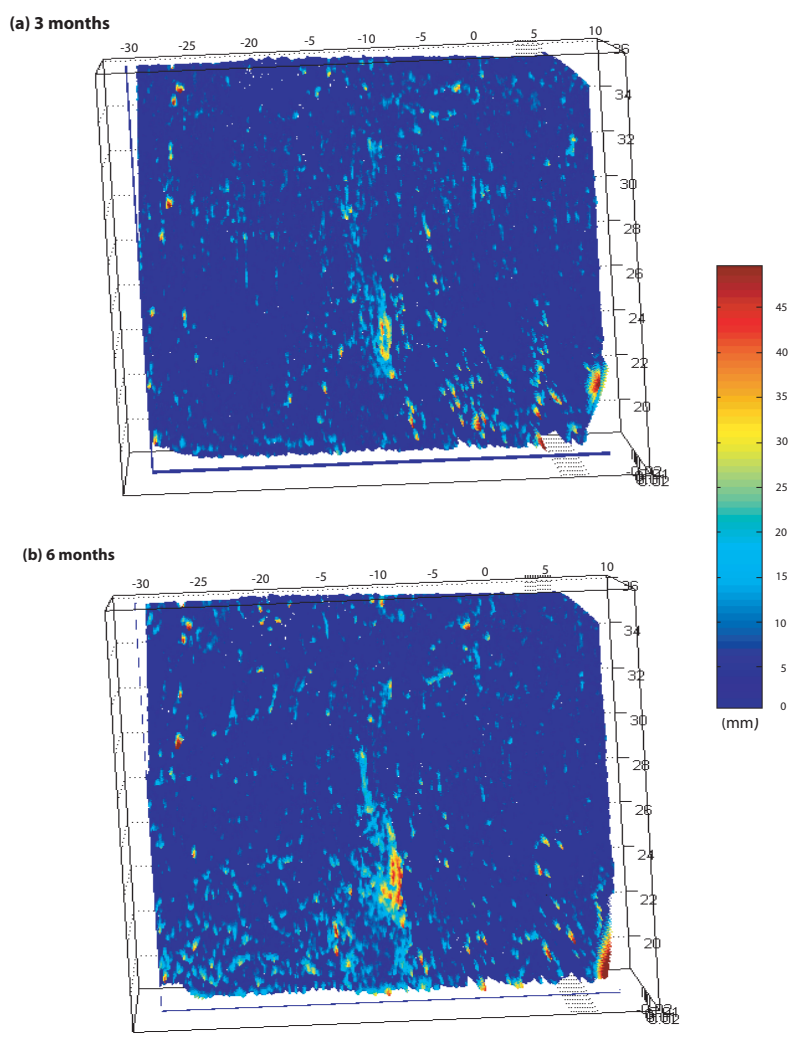

Fig. 7. Filtered displacement measurements prior to the $50 \mathrm{~m}^{3}$ rockfall using the $\mathrm{NN}$ averaging technique. (a) cumulated displacement for 3 months comparison; (b) cumulated displacement for 6 months comparison. A centimetric precursory displacement is observed in the middle of the figure. $\sigma_{\mathrm{NN}}=6.4 \mathrm{~mm}$.

in the same order of magnitude as the error in the RAW DATA comparisons for the plane, the hemisphere and the irregular form $(7.4,10.1$ and $11.2 \mathrm{~mm}$, respectively). The RAW data comparisons show that errors increase with the complexity of the shape (1.0, 1.4 and 1.5 times the standard deviation of the instrumental error, respectively). This could be due to: a low reflectivity, a high incidence angle and/or to a different surface character. On the one hand, several authors (e.g. Soudarissanane et al., 2008; Voegtle et al., 2008) demonstrated the influence of low reflectivity values and large incidence angles in lowering the accuracy. Evidences of these effects are found in the hemisphere: the low values of reflectivity and accuracy were found around the external part of the object (Figs. 1 and 3). By filtering these points, the quality of the overall measurement could be enhanced. On the other hand, the influence of the object material suggested by Voegtle et al. (2008) was negligible in our study.

Precursory displacements lower than $2 \sigma$ cannot be detected with certainty (Eq. 3) using RAW datasets, in the experimental setup, or in the real case study. In contrast, the datasets averaged by a Nearest Neighbour method enabled 
a more precise measurement of these millimetric displacements. Its application to the April 2007 Castellfollit de la Roca rockfall underlines the utility of NN method in real case studies.

New ways to fully exploit the huge quantity of information provided by TLS point clouds are still needed. In our experimental case study, the direction of movement was restricted in 2 dimensions $(z, x)$ and 3 rotations $(x, y, z$ edges $)$. As a result, we defined the vector of comparison along the permitted deformation direction (y, range). However, in a real case study, the direction of displacement is generally not known in advance. This could be a limitation of the comparison technique although the displacement direction can be assessed defining different roto-translation (RT) matrices over discrete parts of the slope (Monserrat and Crosetto, 2008; Oppikofer et al., 2008b), assuming that the nature of the distribution remains constant. Either using the $\mathrm{NN}$ as in the RT techniques, the larger the number of points involved in the calculation, the greater the potential accuracy.

The main advantage of using TLS instead of point based monitoring techniques is the effectively complete measurement of the rock face. If precursory displacement could always be detected on a rock slope prior to a rockfall event, a fixed TLS system collecting a continuous record of the 3-D geometry of the slope could be established. For each point on the square grid described in Sect. 2.3, displacement vs. time could be plotted and evolution of deformation monitored. The temporal prediction of rockfalls and an early warning system could be based on the same framework as that used for a single point measurement, such as inverse velocity time relationships (Fukuzono, 1985).

The NN technique require validation in more cases to test its applicability under real conditions involving different surface materials and different type of failures. Future work will focus on the detection of precursory displacements at different ranges (i.e. from 100 up to $500 \mathrm{~m}$ ) and for variable displacement directions.

Acknowledgements. The academic stay at IGAR-UNIL (ref. AP2007-1852) and a FPU pre-doctoral grant (AP-2004-1852) was financed by the Ministry of Education of Spain. This research was funded by Geomodels Institute, TopoIberia CSD20060004/Consolider-Ingenio2010 and MEC project CGL2006-06596 (DALMASA). We are indebted to our colleagues of IGAR (A. Pedrazzini) and CNRS (J. Travelletti) for their assistance with the experimental setup. Thanks are also due to George von Knorring for improving the English version of the manuscript. And finally, we are very grateful to M.-H. Derron, N. J. Rosser, H. Hack and an anonymous referee for their critical review of the manuscript.

Edited by: M.-H. Derron

Reviewed by: H. Hack and another anonymous referee

\section{References}

Abellán, A., Vilaplana, J. M., and Martínez, J.: Application of a long-range terrestrial laser scanner to a detailed rockfall study at Vall de Núria (Eastern Pyrenees, Spain), Eng. Geol., 88(3-4), 136-148, 2006.

Abellán, A., Vilaplana, J. M., Calvet, J., and García, D.: Seguimiento (monitoring) de laderas rocosas mediante un Láser Escáner Terrestre. Zona de estudio piloto en Castellfollit de la Roca, Cataluña, Geo-temas, 10, 1385-1388, 2008.

Bauer, A., Paar, G., and Kaltenböck, A.: Mass Movement Monitoring Using Terrestrial Laser Scanner for Rock Fall Management, in: Geo-information for Disaster Management, edited by: van Oosterom, P., Zlatanova, S., and Fendel, E. M., Springer, Berlin, 393-406, 2005.

Biasion, A., Bornaz, L., and Rinaudo, F.: Laser Scanning Applications on Disaster Management, in: Geo-information for Disaster Management, edited by: van Oosterom, P., Zlatanova, S., and Fendel, E. M., Springer, Berlin, 19-33, 2005.

Bitelli, G., Dubbini, M., and Zanutta, A.: Terrestrial laser scanning and digital photogrammetry techniques to monitor landslide bodies, Proceedings of the XXth ISPRS Congress Geo-Imagery Bridging Continents, Istanbul, Turkey, ISPRS, 246-251, 2004.

Carrara, A.: Multivariate models for landslide hazard evaluation, Math. Geol., 25, 403-426, 1983.

Crosta, G. B. and Agliardi, F.: Failure forecast for large rock slides by surface displacement measurements, Can. Geotech. J., 40(1), 176-191, 2003.

Davis, P. J.: Interpolation and Approximation, Dover publications, New York, 1975.

Fiani, M. and Siani, N.: Comparison of terrestrial laser scanners in production of DEMs for Cetara tower, Proceedings CIPA XX International Symposium, Torino, 2005.

Fukuzono T.: A new method for predicting the failure time of a slope. In: Proceedings of the fourth international conference and field workshop on landslides, Tokyo: Japan Landslide Society, 145-150, 1985.

Ibsen, M. L. and Brunsden, D.: The nature, use and problems of historical archives for the temporal occurrence of landslides, with specific reference to the south coast of Britain, Ventnor, Isle of Wight, Geomorphology, 15(3-4), Landslides in the European Union, 241-258, 1996.

Ingensand, H.: Metrological aspects in terrestrial laser-scanning technology. In Proceedings of the 3rd IAG/12th FIG Symposium, Baden, Austria. 2006

Lindenbergh, R. and Pfeifer, N.: A statistical deformation analysis of two epochs of terrestrial laser data of a lock, Proceedings of the 7th Conference on Optical 3-D Measurement Techniques, Vienna, Austria, 61-70, 2005.

Monserrat, O. and Crosetto, M.: Deformation measurement using terrestrial laser scanning data and least squares 3-D surface matching, ISPRS J. Photogr. Remote Sens., 63(1), 142-154, 2008.

Oppikofer, T., Jaboyedoff, M., and Keusen, H.-R.: Collapse at the eastern Eiger flank in the Swiss Alps, Nature Geosci., 1(8), 531535, 2008a.

Oppikofer, T., Jaboyedoff, M., Blikra, L. H., and Derron, M.-H.: Characterization and monitoring of the Åknes rockslide using terrestrial laser scanning, in: Proceedings of the 4th Canadian Conference on Geohazards: From Causes to Management, edited 
by: Locat, J., Perret, D., Turmel, D., Demers, D., and Leroueil, S., Presse de l'Université Laval, Québec, Canada, 211218, 2008b.

Rose, N. D. and Hungr, O.: Forecasting potential rock slope failure in open pit mines using the inverse-velocity method, International Journal of Rock Mechanics and Mining Sciences, 44(2), 308-320, 2007.

Rosser, N. J., Petley, D. N., Lim, M., Dunning, S. A., and Allison, R. J.: Terrestrial laser scanning for monitoring the process of hard rock coastal cliff erosion, Quarterly Journal of Engineering Geology and Hydrogeology, 38(4), 363-375, 2005.

Rosser, N. J., Lim, N, Petley, D. N., Dunning, S., and Allison, R. J.: Patterns of precursory rockfall prior to slope failure, J. Geophys. Res., 112(F4), F04014, doi:10.1029/2006JF000642, 2007.

Saito, M.: Forecasting time of slope failure by tertiary creep, in: Proc. 7th Int. Conf on Soil Mechanics and Foundation Engineering, Mexico City, 2, 677-683, 1969.

Slob, S. and Hack, R.: 3-D Terrestrial Laser Scanning as a New Field Measurement and Monitoring Technique, in: Engineering Geology for Infrastructure Planning in Europe, A European Perspective, edited by: Hack, R., Azzam, R., and Charlier, R., Lecture Notes in Earth Sciences, Springer, Berlin/Heidelberg, 104, 179-190, 2004.
Soeters, R. and Van Westen, C. J.: Slope Instability recognition, analysis and zonation. In Landslides: Investigation and mitigation. Special report 247, Transportation Research Board, National Research Council, Washington D.C., 129-177, 1996.

Soudarissanane, S., Lindenbergh, R., and Gorte, B. Reducing the error in terrestrial laser scanning by optimizing the measurement set-up, Proc. of the XXI Congress, The International Society for Photogrammetry and Remote Sensing, ISPRS2008, Vol. XXXVII, Commission V, 3-11 July 2008, Beijing, China, 615-620, 2008.

Teza, G., Galgaro, A., Zaltron, N., and Genevois, R.: Terrestrial laser scanner to detect landslide displacement fields: a new approach, Int. J. Remote Sens., 28(16), 3425-3446, 2007.

Terzaghi, K.: Mechanism of landslides. In Application of geology to engineering practice (Berkeley Volume), edited by: Paige, S., Geological Society of America, Washington D.C., 83-123, 1950.

Voegtle, T., Schwab, I., and Landes, T.: Influences of different materials on the measurement of a Terrestrial Laser Scanner (TLS). Proc. of the XXI Congress, The International Society for Photogrammetry and Remote Sensing, ISPRS2008, Vol. XXXVII, Commission V, 3-11 July 2008, Beijing, China, 1061-1066, 2008.

Zvelebil J. and Moser, M.: Monitoring based time-prediction of rock falls: Three Case-Histories. - Phys. Chem. Earth (B), 26(2), 159-167, 2001. 